\title{
Considerations Regarding the Evolution of Hawaiian Animals
}

\author{
William A. GosLine ${ }^{1}$
}

INTEREST IN THE BIOTAS of oceanic islands is of long standing. There are several reasons for the continuing interest. One is the possibility that insular evolution may in some respects represent a small-scale model of what has occurred on continents. Another is that, despite all the work on the subject, the "hows" and the "whys" of insular evolution remain inadequately answered. Finally, there is the realization that, with the rapid decimation of native insular habitats, it will soon be impossible to study many aspects of the subject (Hubbell, 1967).

The general field of evolution in oceanic animals has been reviewed many times, most recently by Miller (1966) and Carlquist (1965). Zimmerman's summary (1948) for the Hawaiian terrestrial forms is classic. Here, I shall deal with only certain facets of the subject, and I shall cite only those references from the tremendous literature most pertinent to the matter at hand. This selective method of presentation has serious faults, but any attempt to be comprehensive would seem only to obscure the threads of thought that it is the purpose of the paper to present.

Recently, in writing of land plants, Carlquist (1966:433) has spoken of an "insular syndrome of interrelated evolutionary phenomena." Insofar as Hawaiian animals are concerned, what is more striking to me is the diversity of evolutionary results. Such variations occur not only between groups but within some groups as well. For example the evolution of the Hawaiian drepaniid finches has been very different from that of the sea birds.

This diversity of evolutionary results could be exemplified from various animals groups, most notably insects. However, I shall not deal with Hawaiian insects at any length, primarily because of unfamiliarity with them but also

${ }^{1}$ Department of Zoology, University of Hawaii, Honolulu, Hawaii 96822. Manuscript received June 13, 1967. because at the present time they are the subject of an intensive continuing investigation ( $\mathrm{Zim}-$ merman, et al., 1948-; Spieth, 1966:246). Rather, I shall emphasize the evolutionary problems of three Hawaiian animal groups: the inshore fishes, the achatinellid land snails, and the drepaniid finches. As an introduction to the problems involved the evolutionary status of these three groups in Hawaii is summarized briefly.

The Hawaiian inshore fishes (Gosline, 1958; Gosline and Brock, 1960) form part of a marine biota that is essentially similar to, but somewhat impoverished, as compared with that of the Central Pacific islands to the south and west. There are few conspicuous gaps in the Hawaiian marine biota, and, of those that do occur, at least one-the coral genus Acroporawas present in Hawaiian waters in the past (Menard, Allison and Durham, 1962). There seems to be a more or less constant infiltration of non-resident species into the Hawaiian marine biota today, some of which have become established (Doty, 1961), while some have not (Brock, 1948). Intentional introductions of purely marine forms into Hawaiian waters have been mostly unsuccessful. (By contrast, a number of introductions into areas of reduced salinity, e.g., Kaneohe Bay on Oahu, have done quite well.) One of the few that has succeeded, the "Marquesan sardine," has spread throughout the waters of the high Hawaiian Islands in a matter of a few years (Murphy, 1960). Endemism above the species level among Hawaiian fishes is dubious. However, about one third of the inshore species are represented by endemic forms. These can usually be distinguished from Central Pacific counterparts in $100 \%$ of the individuals (for some exceptions, see Gosline, 1955). Aside from a few expected correlations between morphological traits and the relatively cool Hawaiian water temperatures (see, for example, Strasburg, 1955), the morphological characters by which the Hawaiian endemics differ from their Cen- 
tral Pacific counterparts appear to be of a random nature. Within any family of fishes represented in Hawaii, the endemic forms are often the most abundant.

In striking contrast with the Hawaiian marine biota, the native terrestrial biota is highly disharmonic or unbalanced. Great groups of animals, e.g., the amphibians, were completely unrepresented, whereas others, e.g., the land snails and drepaniids, proliferated greatly. Not only new Hawaiian species, but also new genera and families evolved. Among the achatinellid land snails, the genus Achatinella is restricted to the island of Oahu, but some 100 allopatric forms have been described. No relationship between the peculiarities of these forms and the environment they inhabit has, ever been demonstrated. The drepaniid finches seem to have evolved in quite a different way. They inhabited all of the major islands of the Hawaiian chain and some of the smaller islands as well. The most notable differentation within the group is in beak shape, which is associated with feeding habits (Baldwin, 1953). Several different drepaniids were often sympatric.

One of the main differences between the terrestrial and marine environments in Hawaii is in the amount of change caused by man. The terrestrial environment has been largely transformed, in part directly by man via agriculture, etc., but perhaps more by the indirect effect of animals and plants which man has introduced, intentionally or unintentionally. Many of these introductions have now replaced or are replacing the native biota and are directly or indirectly responsible for the restriction or extinction of native forms.

With this brief background, the question of evolutionary processes will be discussed.

Basic to the evolution (or lack of it) that will occur on any island is the matter of which organisms are there and which are not. To exist, an organism must first arrive, and it then must find an environment in which it can survive and reproduce. Both of these aspects depend in part on the isolation of the islandnot isolation in terms of geographical-physical barriers alone, but in terms of these in relation to the ability of the organism to cross them.

The day when isolation could be considered a causal factor has long since passed. However, that it is a powerful controlling factor is generally recognized. This control acts in two related ways. First, it determines which organisms will get to an island and which will not. The selectivity of this filtering factor will increase with increasing isolation and hence will determine in part the extent to which the island biota resembles its parental biota. The greater the difference between these two biotas, the greater will be the change in biological selection pressures on any organism arriving on the island. This point will be discussed later.

Second, any species that establishes itself on an island should, at least for a while, be preserved from contamination by gene flow from the parental population. If the recent introduction to Hawaii of numerous species (e.g., the Marquesan sardine, the African snail, the garden spider, etc.) is any criterion, the initial immigrants can build up a population of millions of individuals in a few years. Beyond this point contamination from gene flow from a few subsequent immigrants will probably have little effect (Gosline, 1958). There are, however, certain important exceptions to this statement. If, in the process of building up a population from initial immigrants, the population becomes debilitated in some way or loses its ability to cope with diseases or parasites which later immigrants may bring with them, then subsequent immigration may matter a great deal.

Of factors actually causing insular evolution only two will be considered. One is natural selection, and the other the series of features associated with small population size.

It is generally agreed that differentation proceeds more rapidly in animal populations on small islands than on large ones. The question is: to what extent is this caused by differences in the selective forces on small islands, and to what extent to factors associated directly with small population sizes. A rather large body of data suggests that many of the peculiarities of small-island forms are not directly selected by the enviroment. Two examples will suffice. Dowdeswell and Ford (1953 and elsewhere) have shown that on the larger islands of the Scilly group the spotting on the wing of the butterfly Maniola jurtina remains about as it 
is on the adjacent Cornish mainland. On the small islands of the group, however, the number of spots on the wing of the females not only varies from island to island, but increases on some and decreases on others. Second, Mertens $(1934: 116)$ has pointed out that the same island may contain a dwarf form of one reptile and a giant form of another. It would be difficult to postulate environmental factors that would select animals in these ways.

If small-population forces are to be postulated for such differences, three possibilities must be considered. The first is the random loss of genes which may occur in small populations by genetic drift (Wright, 1931, etc.). Such a factor would presumably be operative in all small populations. A special case of genetic drift is the phenomenon often called founder effect. This merely expresses the fact that the original immigrants to an island are frequently few in number, and, whether or not they constitute a representative sample, they can bring with them only a small proportion of the alleles present in the parental population (see, for example, Zimmerman, 1948:122, 123). The third possible small-population factor is what Mayr (1954) calls internal selection. In large populations where each gene often has many alleles those which work best as heterozygotes will tend to be selected; on the other hand, in small populations there will be a larger proportion of homozygotes, and alleles which work best in the homozygotic condition will tend to be selected. Thus some shift in internal selection pressure between large and small populations would be expected.

These small-population factors, acting per $s e$, should affect insular immigrants during those initial stages when the population is still small (Fig. 1). But there appears to be no known instance in which a change at this stage has been recorded (cf. Mayr, 1954). Furthermore, it is a generally accepted dictum that, other things being equal, the older the island the greater will be the differentation in its biota; this implies continuous, not just initial, change.

Then how is the differentation that occurs on islands, and more rapidly on small islands, to be explained? King (1955) conducted selection experiments for DDT resistance on two cultures of Drosophila melanogaster. After a dozen or more generations some degree of DDT resistance began to be built up in both lines. But, as judged from crossbreeding experiments, the resistance had been built up differently in the two lines. King (1955:314) states: "The manner in which a line could respond to selection was to some extent determined by the genetic nature of the sample from which it started, and having started along one certain road, it kept on. The inevitable sampling error which occurs when a line is taken from a larger population is very likely the anlage of the genetic individuality of the line. This is, of course, an example of the principle of genetic drift. . . ." The second example is that reported on by Dobzhansky and Pavlovsky (1957). In this experiment ten cultures from a specially developed laboratory stock of Drosopbila pseudo-obscura were started with 20 flies each and compared after 17 months with ten other cultures that did not begin with a reduced number of individuals. Those stocks which had started with 20 flies showed more variation than the controls. Again, Dobzhansky and Pavlovsky conclude (1957:316): "Although the trait studied (gene arrangement in the third chromosome) is subject to powerful selection pressure, the outcome of the selection in the experimental populations is conditioned by random genetic drift."

One aspect of these experiments by King and by Dobzhansky and Pavlovsky may well be of importance for insular evolution. In both instances not only were the original samples small, but the selection that was exerted upon them was far different from the selection of the natural environment from which the flies came. It is as though the samples in the experiments were subjected to an intense selection pressure at right angles to the pressures to which the ancestral "wild" forms had presumably adapted themselves. Possibly some of the alleles intensely selected under the laboratory conditions had been of only peripheral significance to the wild stocks and hence variably represented in them. Such alleles would be more subject to sampling error among small founder populations drawn from the parental stock than those previously under intense positive selection pressure. 
Insular selection pressures (except, perhaps, for species introduced by and dependent on man) are similarly at an angle to those exerted on the mainland parental form. Insofar as the island biota is different from that whence the immigrants came, it is inevitable that the biological selection pressures on islands will differ. Any immigrant to an island will leave behind at least some of the predators, competitors, diseases, and parasites that the parental mainland stock had to cope with. On the other hand the initial immigrants may well have to adapt to new forms of food, cover, etc. (This will be less true only in degree if a species arrives by a series of island hops.)

There is also evidence that selection pressures on small islands are likely to be more radically different than they are on large islands. Thus, on Manana Island, a small outlier of Oahu without domestic cats, the cat flea (Ctenocephalides felis felis) has developed an ectoparasitic existence on rabbits (Oryctolagus cuniculus) (Tomich, et al., in press). Again, in the Balearic Islands off Spain, Eisentraut (1949) showed that on the smaller outliers the food of lizards (Lacerta) differed considerably from that on the main islands. As the normal insect food became more restricted, these lizards added the normally avoided ants to their diets, and on very small islands ate even flower petals and young plant shoots.

Eisentraut believed that this change in diet had a direct metabolic effect resulting in the melanism frequently found in the small-island populations. To me (cf. Dowdeswell and Ford, 1953) it seems more likely that the morphological changes so frequently found in small poulations are in part the indirect effect of altered selection pressures working with time on the, in part randomly, depleted gene pool of small populations. A gradual reintegration of such a gene pool in response to altered selection pressures would likely involve a change in phenotypic characters that are not themselves selected. Such an interpretation (cf. Mayr, 1954; Dobzhansky and Pavlovsky, 1957) seems to me to provide the best available explanation for the often rather heterogeneous differentiating characteristics of insular endemics, e.g., Hawaiian inshore fishes.

The main reason why the peculiarities of
Hawaiian endemic fishes cannot, apparently, be attributed to small-population losses alone is that in many instances the Hawaiian endemics are not characterized by a simple increase in variability (as in Dobzhansky and Pavlovsky's flies) but rather by new and fairly constant characters entirely outside the range of variability of the ancestral populations (as in King's results). Presumably such characters must have arisen through a reintegration and/ or evolution from the ancestral genetic system via direct or indirect selection. The same reasoning would seem to apply to at least some of Eisentraut's melanic lizard populations.

Judging by personal observation and common knowledge concerning recent successful terrestrial introductions of animals to the Hawaiian islands (see also Mead, 1961:180-182; Tomich, et al., in press), there is often (presumably following a longer or shorter period of small numbers) a tremendous initial build-up and "overshoot" in population number (Fig. 1). During my 18 years in Hawaii this has hap-
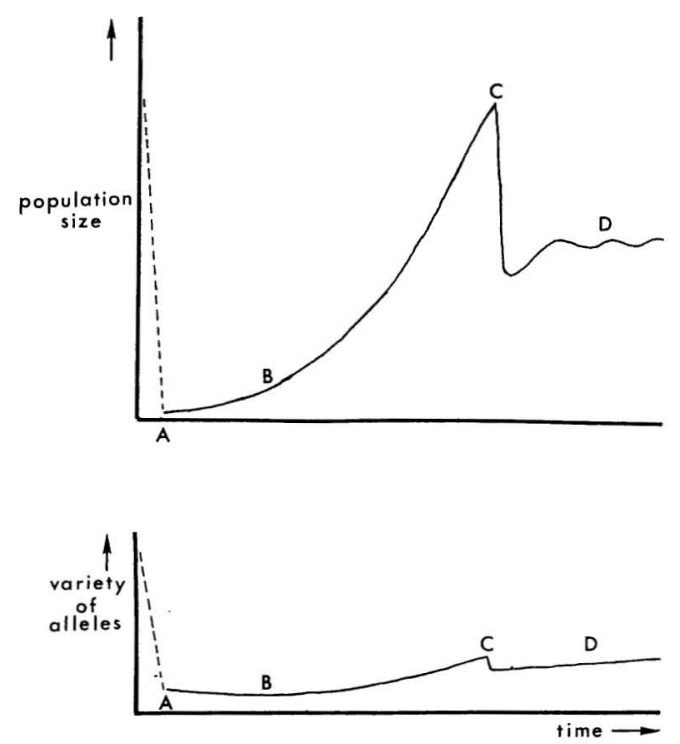

Fig. 1. Theoretical population size (above) and allele variety (below) plotted against time in a terrestrial animal that successfully immigrates into the Hawaiian Islands for the first time. $A$, Date of arrival; $B$, time when population becomes sufficiently large that small-population genetic factors will per se cause no further loss of alleles; $C$, initial peak of abundance; and $D$, subsequent equilibrium. For discussion, see text. 
pened with a garden spider (Argiope appensa) and the giant African snail (Acbatina fulica), among the more conspicuous unintentionally introduced forms. If it can be assumed that this cycle happened in the past with our "native" biota, then certain postulates concerning selection pressures would seem to follow.

First, during the period of initial buildup of an introduced form, selection pressure must be very low. (Apparently the other members of the biota are not initially able to cope with or defend themselves from the new introduction.) However, at some point in the buildup, the population becomes excessive, after which it falls drastically to a new fluctuating equilibrium well below the previous maximum. The nature of the factor that sooner or later kills back the initial overshoot is unknown in any particular instance. There is no reason to believe it is the same in all cases, or that it may not be a combination of factors. What is important to the present argument is that after a period of relaxed selection during the population buildup a very severe selection pressure of some sort appears. Some of the various possibilities are as follows.

First, the animal may eat out the available food supply and then die of starvation. This apparently happened to the rabbits introduced to Lisianski Island (Bryan, 1942:192, 193), and almost but, perhaps significantly, not quite with the rabbits on Laysan (Warner, 1963:6, 7; cf. also Tomich, et al., in press).

On a larger island with a more varied biota a second possible situation might occur after the immigrant population had overeaten its original food supply. Assume that an immigrant adapts itself to an insular food supply as close as possible to that of its parental stock. Assume that, having adapted itself to this insular food source, the immigrant builds up a tremendous population under greatly relaxed selection pressure. At some point it will overshoot its new food supply and a severe competition for food will take place. This selection may preserve the best adapted individuals of the original immigrant type, if enough of the food supply is left. It may also preserve those individuals that have differentiated farthest in the direction of adapting to a new food source (Fig. 2). This theoretical possibility has been set up with the evolution of the Hawaiian
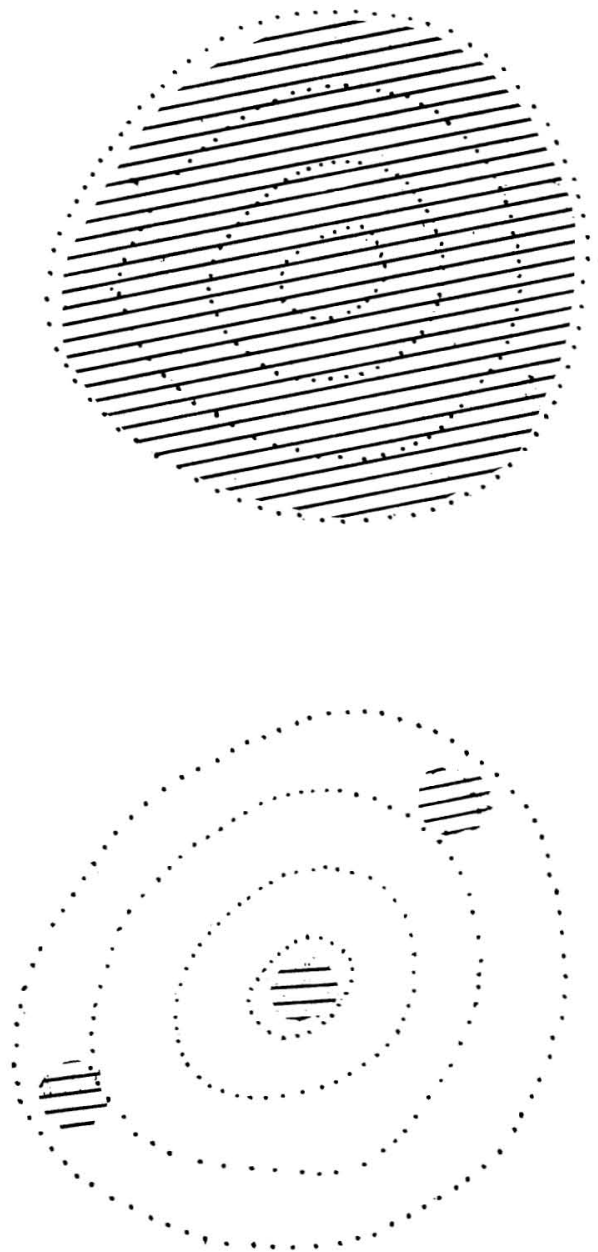

FIG. 2. On a background (dotted contours) representing Sewall Wright's adaptive peak concept are shown (batched areas): above, a theoretical population just before reaching the initial maximum ( $C$ in Fig. 1), and below, the same population after an equilibrium size had been reached ( $D$ in Fig. 1). For discussion, see text.

drepaniid finches, with their various beak types, in mind.

Another possibility is that, following the initial population explosion, some factor other than food supply develops to keep subsequent numbers low. This could be disease or parasitism, some change in other environmental features, or some other factor which would lower the reproductive rate. That the reproductive rate may be diminished has been stressed by Lack (1954). Lack deals especially with changes in egg number in birds. But there is 
another method, in plants at least, by which the replacement rate may be held in check. Rattenbury (1962:354) has said of New Zealand forms:

"Furthermore, the germination of seeds of many native species is a matter of extreme difficulty, as is evidenced by the sporadic appearance of seedlings which often seem to require special conditions for their development. Competent nurserymen have experienced great difficulty in germinating native seeds, often resorting to powerful treatments for breaking the dormancy. In many cases the viable period is very short."

Under conditions of severe interspecific competition, a reduction in the reproduction rate, however accomplished, would seem to be feasible only to the extent that it enables the species to raise a greater number of offspring (Lack, 1954). To drop below that rate would invite replacement by competitors (including possible subsequent immigrants of the same species). If, however, there is very slight interspecific competition, the reproductive rate might theoretically fall to and somewhat below the maximum possible replacement rate without immediate harm. In my opinion, this is what seems to have occurred in many forms among the native terrestrial Hawaiian biota.

If this is true, a species that experienced essentially no natural selection from infra- and interspecific competition during the initial increase might again avoid natural selection after an equilibrium had been reached. In the process, however, the species would of course lose its aggressiveness, especially as compared with subsequently introduced rapidly breeding forms.

Possible examples of a loss in fertility, apparently before any overpopulation has taken place, are provided by the Hawaiian hawk ( $B u$ teo solitarius) and the Hawaiian crow (Corvus tropicus), both of which are, and so far as known always have been, confined to relatively small areas of the single island of Hawaii. In view of the general adaptability of related mainland forms this geographic restriction is most difficult to explain. Possibly here we have a "depauperization of biotype" (Hultén, 1937) arising from small population effects. Such a "depauperization" of course could and prob- ably often does result in a lowering of reproductive capacity.

Returning finally to the achatinellid snails of Oahu, it seems obvious from the isolation of many of the colonies of Achatinella (even before their extensive extermination by the introduced carnivorous snails Euglandina and Gonaxis; see Krauss, 1964) that they were not spreading. Presumably they can only have been developed from some more "aggressive" ancestral form (and/or a less dissected topography than exists today). But given the more recent isolation in separate colonies there seems to be no reason why, in the absence of further gene flow, each colony should not evolve in its own way as do so many other small popula. tions, particularly land snails. A basically similar provisional hypothesis has been advanced by Carson (1966:405) to explain the forma. tion of Hawaiian species of Drosophilidae.

\section{ACKNOWLEDMENTS}

My acquaintance with this subject has been gained over the years through the kind help of colleagues too numerous to mention. For specific suggestions and comments on the manuscript I wish sincerely to thank Dr. A. H. Banner, Dr. E. A. Kay, and Dr. C. H. Lamoureux of the University of Hawaii, and Dr. Y. Kondo of the Bishop Museum, all of whom have been residents of Hawaii and interested in the Hawaiian biota for much or most of their lives.

\section{REFERENCES}

Baldwin, P. H. 1953. Annual cycle, environment and evolution in the Hawaiian honeycreepers (Aves: Drepaniidae). Univ. Calif. Publ. Zool. 52:285-398, pls. 8-11, 12 figs.

Brock, V. E. 1948. An addition to the fish fauna of the Hawaiian Islands. Pacific Sci. $2: 298$.

Bryan, E. H., JR. 1942. American Polynesia and the Hawaiian Chain. Tongg Publishing Co., Honolulu. 253 pp., illus.

Carlquist, S. 1965. Island Life. The Natural History Press, Garden City, New York. viii + 451 pp., 7 col. pls., text figs.

- 1966. The biota of long-distance dis- 
persal. IV. Genetic systems in the floras of oceanic islands. Evolution 20:433-455, 2 figs.

Carson, H. L. 1966. Chromosomal Races of Drosophila crucigera from the Islands of Oahu and Kauai, State of Hawaii. Univ. Texas Publ. No. 6615, pp. 405-412, 2 figs.

Dobzhansky, T., and O. Pavlovsky. 1957. An experimental study of interaction between genetic drift and natural selection. Evolution 11:311-319, 2 figs.

Doty, M. S. 1961. Acanthophora, a possible invader of the marine flora of Hawaii. Pacific Sci. 15:547-552.

Dowdeswell, W. H., and E. B. Ford. 1953. The influence of isolation on variability in the butterfly Maniola jurtina L. Symp. Soc. Exptl. Biol. 7:254-273, 2 maps.

Eisentraut, M. 1949. Die Eidechsen der spanischen Mittelmeer Inseln. Mitt. Zool. Mus. Berlin 26:1-225, 10 col. pls., 46 text figs.

Gosline, W. A. 1955. The inshore fish fauna of Johnston Island, a Central Pacific atoll. Pacific Sci. 9:442-480, 4 figs.

1958. The nature and evolution of the Hawaiian inshore fish fauna. Proceedings of the Eighth Pacific Science Congress, Vol. 3, pp. 347-357, 1 fig.

- and V. E. BRock. 1960. Handbook of Hawaiian Fishes. University of Hawaii Press, Honolulu. ix +372 pp., 277 figs.

Hubbell, T. H. 1967. Systematics and the International Biological Program. Systematic Zoology 16:97-99.

Hultén, E. 1937. Outline of the History of Arctic and Boreal Biota during the Quaternary Period. Stockholm. 168 pp.

KING, J. C. 1955. Evidence for the integration of the gene pool from studies of DDT resistance in Drosophila. Cold Spring Harbor Symposia on Quantitative Biology. Vol. 20, pp. 311-317.

KRAUSS, N. L. H. 1964. Investigations on biological control of Giant African (Achatina fulica) and other land snails. Nautilus 78: 21-27.

LACK, D. 1954. The evolution of reproduction rates. In: Huxley, Hardy and Ford, eds., Evolution as a Process, pp. 143-156. Collier, N.Y.

MAYR, E. 1954. Change of genetic environment and evolution. In: Huxley, Hardy and Ford, eds., Evolution as a Process, pp. 157180, 3 figs. Collier, N.Y.

MeAd, A. R. 1961. The Giant African Snail. University of Chicago Press, Chicago. xvi + 257 pp., 15 figs.

Menard, H. W., E. C. Allison, and J. W. Durham. 1962. A drowned Miocene terrace on the Hawaiian Islands. Science 138: 896-897.

Mertens, R. 1934. Die Insel-Reptilien, ihre Ausbreitung, Variation und Artbildung. Zoologica (Stuttgart) 32:1-209.

Miller, A. H. 1966. Animal Evolution on Islands. In: R. I. Bowman, ed., The Galapagos, pp. 10-17. University of California Press.

Murphy, G. I. 1960. Introduction of the Marquesan sardine, Harengula vittata (Cuvier and Valenciennes), to Hawaiian waters. Pacific Sci. 14:185-187.

Rattenbury, J. A. 1962. Cyclic hybridization as a survival mechanism in the New Zealand forest flora. Evolution 16:348-363, 5 figs.

SPIETH, H. T. 1966. Courtship Behavior of Endemic Hawaiian Drosophila. Univ. Texas Publ. No. 6615, pp. 245-314.

Strasburg, D. W. 1955. North-south differentiation of blenniid fishes in the Central Pacific. Pacific Sci. 9:297-303.

Tomich, F. Q., C. H. Lamoureux, and N. WILson. In press. Ecological factors on Manana Island, Hawaii. Pacific Sci.

WARNER, R. E. 1963. Recent history and ecology of the Laysan Duck. Condor 65:3-23, 8 figs.

Wright, S. 1931. Evolution in Mendelian populations. Genetics 16:97-159.

ZimmermaN, E. C. 1948. Insects of Hawaii. Vol. 1. Introduction. University of Hawaii Press, Honolulu. xvii +206 pp., 52 figs.

—_ et al. 1948-. Insects of Hawaii. Eleven volumes published so far. University of Hawaii Press, Honolulu. 